\title{
Quality differences of gilthead sea bream from distinct production systems in Southern Europe: Intensive, integrated, semi-intensive or extensive systems
}

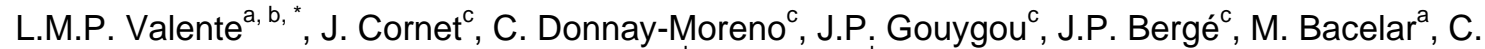 \\ Escórcio $^{a}$, E. Rocha ${ }^{\mathrm{a}, \mathrm{b}}, \mathrm{F}$. Malhão ${ }^{\mathrm{b}}$ and M. Cardinal ${ }^{\mathrm{c}}$ \\ ${ }^{a}$ CIMAR/CIIMAR - Centro Interdisciplinar de Investigação Marinha e Ambiental, Universidade de \\ Porto, Rua dos Bragas, 289, 4050-123 Porto, Portugal \\ b ICBAS - Instituto de Ciências Biomédicas de Abel Salazar, Universidade do Porto, Largo Prof. Abel \\ Salazar, 2, 4099-003 Porto, Portugal \\ c IFREMER, Laboratoire Science et Technologie de la Biomasse Marine, F-44311 Nantes 03, France \\ *: Corresponding author : L.M.P. Valente, Tel.: +351 223401825; fax: +351 223390608, email address : \\ Ivalente@icbas.up.pt
}

\begin{abstract}
:
The quality of gilthead sea bream from distinct production systems and geographical locations in Southern Europe was evaluated to differentiate aquaculture products from extensive, integrated and semi-intensive systems from the ones produced intensively. This work analysed the external appearance of fish, yields after filleting as well as nutritional, sensory and histological characteristics of the muscle. The results showed that the yellow-golden line between eyes and the shiny red spot on the gill cover can be important and easy criteria to discriminate aquaculture products. Trimming losses are higher in fish from intensive systems. Lipid content of fish from extensive systems was significantly lower than values observed for fish reared intensively. Samples from the integrated and extensive systems showed the best $n-3 / n-6$ ratio, contrarily to intensive systems, but it is difficult to establish clear quality markers to differentiate gilthead sea bream according to the rearing system. Regarding sensory characteristics, the sea bream flesh from intensive systems seems firmer and denser, having smaller white fibres and higher density of fibres in the dorsal muscle. The taste and odour of fatty fish was less strong in fish reared in non-intensive conditions, but extensive rearing in earthen pond is more propitious to the development of certain characteristics related to the environment.
\end{abstract}

Keywords: Flesh quality parameters; Fatty acids profile; Sensory evaluation; Histological muscle characteristics; Rearing systems in aquaculture; Quality indicators in fish 


\section{Introduction}

It is generally accepted that eating fish is beneficial for human health, mainly due to the protective effect of fish lipid against cardio-vascular diseases. Global fish consumption per capita has increased over the past four decades, rising from $9.0 \mathrm{Kg}$ in 1961 to an estimated $16.7 \mathrm{Kg}$ in 2006 (FAO, 2009). Thus, and considering the fisheries failure to meet the growing world demand for aquatic food, aquaculture is predicted to play a major role in meeting an important part of fish world's demands for human consumption. But due to environmental risks of eutrophication of intensive production aquaculture systems in coastal areas, in particular in costal lagoons, and the public image of its products (Verbeke, Sioen, Brunsø, De Henauw, \& Van Camp, 2007), the positive effects of traditional extensive coastal and semi-intensive aquaculture systems, including environmental protection and restoration in areas of particular ecological interest have been clearly recognised within EU policy (see EU SEACASE project). Indeed, several extensive and semi-intensive systems developed during the last centuries are still effective economic activities in many coastal areas of Southern Europe, having a significant socio-economic impact (Hussenot, 2003). More recently, the global concerns about environmental issues and the increasing demand of consumers on food quality and on cultivated species welfare (Frewer, Kole, Kroon, \& Lauwere, 2005) threw extensive and semi-intensive aquaculture products to the front scene. However, little effort has been devoted to exploring quality differences between these products and the ones from intensive fish farming.

Gilthead sea bream (Sparus aurata) is the major farmed fish species in the Mediterranean region with an estimated production of 129,000 ton in 2008 (FEAP, 2008). Although a considerable amount of work has been done in recent years on seabream quality (Reviewed by Grigorakis, 2007; Grigorakis, Alexis, Taylor, \& Hole, 2002; Tejada, Huidobro, \& Mohamed, 2006; Vergara, et al., 1999), comparative data on fish obtained from different culture systems is extremely scarce (Ferreira Pinto, Nunes, \& Cardoso, 2007; Flos, Reig, Oca, \& Ginovart, 2002). From the consumer's point of view, it would be desirable to establish a general quality scheme for this species that could help consumers differentiating aquaculture products in Southern Europe. An example of well succeeded labelling is the case of the French 'Label rouge' for seabass (Bermejo, 2000). Extensive literature correlated environmental conditions and farming techniques, including water salinity and temperature, rearing density, feeding procedures and slaughtering conditions, with growth rate and quality criteria in several fish species (Bagni, et al., 2007; Calabretti, Cateni, Procida, \& Favretto, 2003; Dendrinos \& Thorpe, 1985; Dias, Conceição, Ribeiro, Borges, et al., 2009; Eroldogan, Kumlu, \& Aktas, 2004; Ferreira Pinto, et al., 2007; Shearer, 1994). The current trend in intensive fish production is to increase the lipid content in diets to spare proteins, to improve feed conversion and to decrease the amount of waste produced by fish. However, these diets alter body composition and slaughter quality in several species (Cowey, 1993; Hillestad \& Johnsen, 1994; Vergara, et al., 1999). As nutritional value and sensory attributes of the flesh are the main determinants of fish quality as perceived by the consumer (Grigorakis, 2007), a shift towards a lower usage of finite marine-harvested resources to develop more sustainable feeds is a challenge facing scientific community and the aquaculture industry in order to avoid remarkable changes in sensory attributes and to provide the adequate levels of long-chain omega-3 fatty acids for human nutrition (Bell, Henderson, Tocher, \& Sargent, 2004; Caballero, et al., 2002; Izquierdo, et al., 2005; Pratoomyot, Bendiksen, Bell, \& Tocher, 2010). In this context, questions about quality of farmed products, rearing conditions and environmental impact of aquaculture became important concerns for both the producer and the consumer (Frewer, et al., 2005). 
The quality of gilthead sea bream from a wide variety of production systems and geographical locations in Southern Europe (Portugal, Spain, France, Italy and Greece) was evaluated in this study to try differentiating aquaculture products from extensive, integrated and semi-intensive systems from the ones produced intensively. In order to compare flesh quality traits of aquaculture products a multidisciplinary approach was applied, including both sensory properties and nutritional value. This work analysed important flesh quality traits in each sample: biometric and physical measurements (size, length, yield and colour), nutritional aspects (including fat and protein content, fatty acids and amino acid profile), sensory characteristics using a trained panel and the histological characteristics of the muscle. Multivariate data analysis as principal component analysis (PCA) were performed to evidence the parameters with the most discriminative power and to highlight the main relationships between criteria in order to identify suitable indices able to differentiate aquaculture products.

\section{Materials and methods}

\subsection{Fish sampling}

Gilthead sea bream of standard commercial size (300-400 g) were obtained from distinct production systems and geographicallocations in Southern Europe: one extensive system in the salt-marshes area surrounding the Bay of Cadiz (Spain) and a large lagoon system in Northern Adriatic in Italy that covers a total surface of about 36,323 ha, split in 92 "valli da pesca", with surface area ranging from 10 to 10,000 ha (Valliculture); semi-intensive polyculture in earthen ponds in South Portugal (4 farms); one integrated system associating algae, shellfish and fish in earthen ponds using the enriched water effluent of a seabass hatchery as a fertiliser to enhance the productivity of an extensive compartment (Oléron island, France); 24 intensive fish farms from Greece, France (Atlantic and Mediterranean coast) and Spain. The pond size and rearing densities differed among farms and environmental water temperature depended on the farm location. Hussenot (2003) has recently reviewed these existing practices in European coastal wetlands. The productivity of the traditional extensive systems in earthen ponds ranged between 100 and $500 \mathrm{~kg} / \mathrm{ha} / \mathrm{year}$ depending on areas and years; fish were exclusively fed on natural food from the ponds and no supplementary feeding was provided. The semi-intensive systems also covered large areas, ponds ranging from one to several hectares, and density ranging from 0.5 to 4.5 $\mathrm{kg} / \mathrm{m}^{2}$ at the end of the production cycle. These fish were fed full formulated feeds containing $54 \%$ crude protein and $17 \%$ crude lipid. Fish of integrated systems were reared in an intensive farm, and then transferred to an extensive system for 6 months in a first experiment and 2 months in a second. In this integrated system, fish were reared at a density of $0.03 \mathrm{~kg} / \mathrm{m}^{2}$. In intensive systems fish were grown in both floating cages and land ponds at high densities $\left(10-70 \mathrm{~kg} / \mathrm{m}^{3}\right)$, and were fed formulated feeds containing $44-48 \%$ crude protein and $18-20 \%$ crude lipid.

All fish were sampled after a starving period of 2-3 days and slaughtered by immersion in slurry ice. The sampled fish were kept in ice and analysed 4 days after slaughtering. The yield was determined on twenty fish at each step of the filleting process. Composition analysis was realised on three grinded whole fish as well as on the flesh of three other trimmed fish. Colour of the fillets was measured on five fish and 12 fish were necessary for sensory evaluation. Histological variables were measured in transversal slices from at least 3 fish from each fish farm to evaluate the muscle structure. 


\subsection{Body morphological traits and external appearance}

At each sampling, thirty fish from each farm were individually weighed and measured, and the condition factor was determined. The external appearance of fish was described by two people, the same along the study, considering global skin colour and presence and intensity of interorbital yellow line or orange-red spot on the head side on the gill cover. It was a qualitative description. Twenty fish were gutted, filleted and trimmed always by the two same persons. Trimming procedure allowed peritoneum, bones, visible dorsal fat depot and visible belly flap fat to be eliminated. A fillet with skin was obtained. Loss were calculated at each step and expressed as a percentage of total weight of whole fish, for viscera, head and bones, trimmed part (peritoneal deposit and dorsal fat deposit). The edible fraction of the fish was calculated in the same way.

\subsection{Proximate analyses, fatty acid and amino acid profile}

For each batch of fish received from each farm, three grinded whole fish were pooled. The flesh of trimmed fillets, the edible part of the fillet i.e. without perivisceral fat deposit and subcutaneous adipose tissue, from three other fish was also grinded and pooled. Both whole body and flesh samples were freeze dried and all samples were analysed in duplicates. Dry matter content was determined after oven drying $10 \mathrm{~g}$ of sample at $103^{\circ} \mathrm{C}$ for one night. Ash content was carried out by ignition of $1 \mathrm{~g}$ of sample at $600^{\circ} \mathrm{C}$ for $24 \mathrm{~h}$ (AOAC, 2006). Lipids were extracted according to the Folch procedure (Folch, Lees, \& Stanley, 1957). Total lipid content was determined gravimetrically after solvent extraction and evaporation. The total nitrogen content was determined on $200 \mathrm{mg}$ of sample using a micro system of Kjeldahl method (Crooke \& Simpson, 1971). Crude protein was estimated by multiplying the total nitrogen content $(\% \mathrm{~N})$ by the factor 6.25 . Fatty acid profile was obtained by separation and quantification of the fatty acids methyl esters using a capillary column with high polarity (BPX 70, 60m long, $0.25 \mathrm{~mm}$ internal diameter, $0.25 \mu \mathrm{m}$ film thickness, stationary phase cyanopropyl siloxane) using a gas chromatograph Perkin Elmer Autosystem equipped with a FID detector $\left(300^{\circ} \mathrm{C}\right)$. The EZ:faast ${ }^{\mathrm{TM}}$ procedure (Phenomenex, USA) has been used for the amino acid analysis of protein. An acid hydrolysis with $6 \mathrm{~N} \mathrm{HCl}$ was carried out on 10mg of freeze-dried sample. The EZ:faast amino acid analysis procedure consists of a solid phase extraction step followed by derivatization and liquid/liquid extraction with the EZ faast kit. Derivatized samples are quickly analysed by gas chromatography on Zebron ZB-AAA GC column $(10 \mathrm{~m} \times 0.25 \mathrm{~mm})$ of chromatograph Perkin Elmer Autosystem XL with FID detection $\left(320^{\circ} \mathrm{C}\right)$. Helium was the carrier gas used at a constant flow rate of $1.5 \mathrm{~mL} / \mathrm{min}$. The amino acids were expressed in percent of total amino acids.

\subsection{Histological characteristics}

Fish were individually weighed to the nearest $\pm 0.1 \mathrm{~g}$ and measured (fork length) to the nearest $\pm 0.1 \mathrm{~cm}$. After that, the fins were cut, the scales gently removed and one cross-sectional body slab (2-3 $\mathrm{mm}$ thick) was removed from the region immediately before the first dorsal fin. The samples (3 fish per fish farm) were fixed in Bouin's (Panreac, Barcelona, Spain) fluid for 72 hours, with sporadic shaking. After fixation, and under a stereomicroscope, each slab was longitudinally cut in two (right and left) equal-sized (mirror) halves. The pieces were then routinely dehydrated in a graded ethanol series, cleared in xylol, and finally embedded in paraffin. Three $10 \mu \mathrm{m}$-thick section were cut per block, and then stained with haematoxylin-eosin before being 
coversliped for morphometric analysis. Morphometric measurements were made on dorsal muscle transversal sections using an interactive image analysis system (Olympus Cell*Family), captured by CCD-video camera (ColorView Soft Imaging System, Olympus) and a light microscope (BX51, Olympus, Japan). Fish dorsal crosssectional area $(A)$, in $\mathrm{mm}^{2}$, was computed by the software after circumscribing half of the physical limits of the whole dorsal section. Such delimitation was made using the mouse and under a $1.25 \times$ objective lens. An estimate of the total dorsal area [A (dorsal area)] was obtained by doubling the computed value. The relative area occupied by a particular tissue component $\left[\mathrm{A}_{\mathrm{A}}\right.$ (tissue area)], either dorsal white or adipose tissue, was delimited by circumscribing the physical limits of interest in half of the section, using the mouse and under $1.25 \times$ objective lens. An estimate of the total dorsal white muscle area or adipose area was made by doubling the computed value. The relative numbers of white muscle fibres per unit area $\left(\mu \mathrm{m}^{2}\right)$, within the respective muscle zones $\left[N_{A}\right.$ (fibres)], were estimated as follows: $N_{A}$ (fibres) $=\Sigma N$ (fibres) $\div \Sigma$ [a (sampled field)] where $\Sigma N$ (fibres) is the total number of fibres counted over three sampled fields in a section, selected according to Rowlerson et al (1995), and "a" is the total area of the fibre counting fields. The total number of white muscle fibres per dorsal cross section $(\mathrm{N})$ was estimated as follows: $N$ (fibres) $=N_{A}$ (muscle fibres) $\times A_{A}$ (muscle) where $N_{A}$ is the number of white muscle fibres per unit area $\left(\mu m^{2}\right)$ and $A_{A}$ the relative area occupied by a particular tissue component. Finally, the mean individual muscle fibre area [ā (fibre)] was estimated by circumscribing the physical limits of the fibre section. The corresponding diameter was computed as follows: $\mathrm{D}$ (muscle fibre) $=2 \overline{\mathrm{a}}^{0.5} \pi^{-0.5}$. All measurements of white fibres were made with the $20 \times$ objectives over three sampled fields within a section, selected according to Rowlerson et al (1995).

\subsection{Colour measurement}

Colour was determined from five fillets, using a Spectrocolorimeter CM-2500d with a D65 light source and a $10^{\circ}$ observer (Konica Minolta sensing Europe, France) calibrated to black and white standards. The tristimulus $L^{*}, a^{*}, b^{*}$ measurement mode (CIE, 1976) was used as this relates to human eye response to colour. The $L^{*}$ variable represents lightness $\left(L^{*}=0\right.$ for black, $L^{*}=100$ for white), while the $a^{*}$ scale represents the red/green dimension, with positive values for red and negative ones for green. The $b^{*}$ scale represents the yellow/blue dimension, with positive values for yellow and negative ones for blue (Dordet, 1990). Colour was measured on five different spots on dorsal part of each fillet, in raw and cooked presentation. Results are shown as the mean of these measurements.

\subsection{Sensory analysis}

Twenty one panellists, belonging to the IFREMER staff and selected for their experience on fish characteristics evaluation, carried out conventional profiling (ISO13299, 2003) to evaluate the sensory properties of sea bream. Descriptors were selected in a previous study on sea bass $(\mathrm{Ky}, 2007)$ and participated in two training sessions using different fish species (sea bream, sole and pike perch). These sessions allowed to find a consensus around sensory description of each species and to check the panellists' understanding of the descriptors. Sensory criteria chosen for sea bream cooked fillet related to the appearance, odour, flavour and texture; for odour: global intensity, fat fish, marine-iodin like, boiled milk, earthy; for appearance, colour homogeneity, white colour, coagulated proteins, brown spots, black stria, fat droplets in gravy; for texture, firmness, density of the flesh, moisture, fibrous texture, sticky texture, chewiness, fat film and for flavour, global intensity, fat fish, potato, earthy, salty, bitter, metallic. In a first part of the study (Intensive 1, I1), 18 samples from 
intensive production systems were submitted to evaluation in six sessions; three samples were presented per session (Cardinal, Cornet, Donnay-Moreno, Gouygou, et al., 2010). Then each sample from the other aquaculture systems (extensive, semiintensive and integrated system) was successively analysed in comparison with a sample from intensive aquaculture (Intensive 2, 12). Panellist received two or three samples per session, blind coded with 3-digit numbers. All samples were from the central part of a fillet, without skin, cooked in a glass bowl covered with a cap. After cooking in a microwave oven (Samsung) during $1 \mathrm{~min} 30$ s to $1 \mathrm{~min} 50$ s at $600 \mathrm{~W}$, according to the number of samples, the fillets were randomised and served simultaneously. Panellists were asked to consume the dorsal part of the fillet. Sessions were performed in individual partitioned booths equipped with a computerised system (Fizz system, Biosystèmes, Dijon, France). These conditions were conducive to concentration and avoided communication between assessors and disturbance by external factors (ISO, 8589, 1988). Panellists rated the sensory attributes on a continuous scale presented on a computer screen, ranging from low (0) to high intensity (10).

\subsection{Statistical analysis}

Statistical analyses followed methods outlined by Zar (1999). The mean, standard deviation, analysis of variance, Tuckey multiple range test and correlations among parameters were performed using Statgraphics Plus Centurion XV.I software (Sigma Plus, Paris, France). Body weight was used as a co-variate in all statistical analysis concerning muscle cellularity. The significant statistical level was set at $p<0.05$. Multivariate data processing as principal component analysis (PCA) was performed on the samples sensory scores averaged over assessors using Uniwin 6.1 software (Sigma Plus). This procedure was chosen to summarize in few dimensions the key information in sensory data while explaining the differences between samples. This PCA was based on the correlation matrix, so all attributes were given the same importance whatever the range of the scale used. In order to identify a possible session effect due to the experimental design, the first 18 samples from the intensive system were labelled as 11 whereas intensive samples used for direct comparison with samples from other rearing systems were labelled as 12 .

\section{Results}

\subsection{Body morphological traits and external appearance}

The body traits are reported in Table 1 . The condition factor of fish was similar among the various systems. All fish have also presented equivalent body length, although fish from semi-intensive systems weighted significantly less than those from the extensive or integrated systems. Qualitative description of external appearance showed distinct features between fish from intensive system and all other systems (semi-intensive, extensive or integrated). Fish from intensive farms did not present any yellow band between eyes, or any orange-red spot on the side of the head, presenting a general darker colour on the dorsal part of the body. On the other hand, fish from integrated and extensive system developed an intense interorbital yellow band and a shiny orange patch on the gill cover. These same characteristics were observed on fish from semi-intensive system but with lower colour intensity. Regarding commercials traits a 
significant difference is noticed on trimming losses for intensive-reared fish compared to the extensive ones, but no significant differences resulted on the edible part.

\subsection{Whole body composition and chemical composition of the fish fillets}

The whole body lipid composition of sea bream reared in extensive systems was the lowest, whereas the protein content was the highest (Table 1). The flesh protein content and the total flesh amino acids of sea bream did not vary significantly among rearing conditions (Table 2). Fish showed similar total essential amino-acids (42-43\%), thought semi-intensive fish had the highest isoleucine percentage. The ratio essential/non essential amino-acids was similar among rearing systems. The significant differences registered in whole body lipid content were not totally reflected in terms of flesh total lipids (Table 3), although a clear trend for a lower flesh fat content in both integrated and extensive fish could be observed (5.1-6.6 vs 8.1-9.3).

Analytical results of fatty acids in sea bream flesh (Table 3 ) generally showed high levels of saturated (35-41\%) and monounsaturated (36-45\%) fatty acid groups and a relatively low level (14-29\%) of polyunsaturated fatty acids (PUFA). Palmitic acid (C16:0), oleic acid (C18:1n-9) and linoleic acid (C18:2n-6) were always the main constituents of the muscle fatty acid profile. The large variation observed within intensive samples, on both $\mathrm{C} 18: 2 \mathrm{n}-6$ and total $n-3$ polyunsaturated fatty acids values, does not allow showing significant differences among rearing systems, though global tendencies appear. The n-3 polyunsaturated fatty acids fraction varied from $7.7 \%$ in the intensive system to $20 \%$ in the integrated one. Moreover, significant differences could be observed on the levels of docosapentaenoic (DPA, C22:5n-3) and docosahexaenoic (DHA, C22:6n-3) acids among rearing systems. Fish from the semi-intensive and integrated systems displayed significantly higher levels of DHA, and fish from integrated systems had also the highest levels of DPA. The same trend was observed for eicosapentaenoic acid (EPA, C20:5n-3) but without statistical significance.

\subsection{Colour measurement and histological characteristics}

The colour of sea bream flesh evaluated by instrumental analysis in this study (Table 4) reflected a great variability among rearing systems both in raw and cooked fillets. Most of the colour parameters measured on fish from integrated system are significantly different from those measured on fish from other systems; integrated fish had a significantly lower lightness $\left(L^{*}\right)$, but a significantly higher $b^{*}$ value, corresponding to a yellow colour, on both raw and cooked fillets. Semi-intensive system samples had a lower $b^{*}$ value compared to those observed in fish from integrated system, but these values were significantly higher than those observed in intensive and extensive samples. Regarding $a^{*}$ parameter measured on raw flesh, samples from the semiintensive and the integrated system displayed the two lowest values compared to samples from intensive and extensive system. After cooking, fish from intensive system had the lowest value, indicating the lowest redness colour.

Muscle cellularity results are presented in Table 4 . The total mean cross-sectional area occupied by the subcutaneous adipose tissue in the dorsal area did not vary significantly $(P>0.05)$ among systems. Fish from intensive and integrated systems showed significantly smaller white fibre diameters and higher fibre density compared to fish from semi-intensive or extensive systems. The percentage of small-sized white fibres was also highest in fish from intensive and integrated systems. Concerning red 
muscle, fish from the extensive system had significantly larger red fibres and hence a lower red fibre density than all other systems.

\subsection{Sensory evaluation}

To have a global view of the sensory characteristics of sea bream from different rearing system, a standardized principal component analysis (PCA) has been performed on the panel mean score obtained for each descriptor and each sample (Figure 1a). The first axis, which account for $26.4 \%$ of total inertia is mainly created by descriptors of global odour and earthy notes, by criteria of appearance, as white colour and homogeneity of the colour and also by descriptors of texture such as firmness, density of the flesh, fibrous texture and chewiness. The second axis (17.0\% of inertia) is defined by the global intensity of flavour, fat flavour and fat film perception in mouth. The projection of the samples on this plane (Figure 1b) allows highlighting the main differences between samples. Samples from extensive system are clearly discriminated on the first axis due to their odour and flavour characteristics. Samples from extensive systems (Ext1 and Ext2) displayed an intense earthy odour and flavour. The two samples from integrated systems (Integrated_2m and Integrated_6m) also presented an intense odour and flavour, but distinct from those described in extensive products; fish from integrated system evidenced a characteristic marine/iodine like odour and flavour (more visible on plane 3-4 not presented). In fact, the one way analysis of variance performed on sensory results with production system as main effect showed that earthy odour and flavour and marine/iodine odour have the highest Fisher values, and were therefore identified as the criteria with a higher power to discriminate samples according to the rearing system. Samples from extensive systems showed a significantly higher earthy odour and flavour $(p<0.05)$, whereas sea bream from the integrated system exhibited a significantly higher marine/iodine odour $(p<0.05)$. Compared to samples from intensive production system, the texture of extensive products presented a tendency $(p<0.10)$ to a higher moisture. The right-sized location of the samples from intensive production system (I1 and I2), as can be observed in Figure $1 \mathrm{~b}$, is explained by a significantly whiter flesh colour, a more dense and fibrous texture, as well as more sticky and firm texture than extensive samples. On this figure, it is also interesting to notice a certain variation within intensive system samples related to fat odour and flavour intensity and perception of a fatty film in mouth. Samples from semi-intensive system located in the medium part of the figure had intermediate characteristics between extensive and intensive system samples, but closer to intensive one regarding the general characteristics of odour.

\subsection{Relation between the various quality parameters}

In order to assess relationships between the different parameters of quality measured in this study, the correlation between principal component of the PCA performed on some chemical, physical and histological parameters and sensory variables have been calculated (Figure 2). The first axis showed a negative correlation between the diameter of the muscle fibres and both the number of small fibres and the density of the fibres. A significant correlation appeared between the first principal component and sensory descriptors of texture as fibrous texture and firmness of the cooked flesh. Fibrous texture was positively correlated with the number of small fibres (person correlation $=0.48$ ). Flesh firmness was negatively correlated with white fibre diameter (person correlation $=-0.45$ ), but positively correlated with both white fibre density and the number of small fibres ( 0.47 and 0.51 , respectively). A weak relation was also perceived between muscle structure and the density scores of the cooked fillet, but lacked statistical significance. These results allowed to confirm some differences 
already noticed between fish i.e. that intensive samples have larger number of small fibres, a higher density of white fibres and a firmer and denser texture, whereas extensive or semi-intensive have a higher fibre diameter.

The second axis of the PCA showed significant relationship between lipid content, subcutaneous adipose tissue, fatty flavour, the perception of fatty texture (fat film in the mouth) and sticky texture, but also with the lightness measured on cooked fillet $\left(L^{*} C\right)$. All these parameters are negatively correlated with the yellow colour on cooked flesh $\left(b^{*} \mathrm{c}\right)$ and the percentage of $n-3$ polyunsaturated fatty acids. On the plane 3-4 (not shown), it is also interesting to note a significant correlation between the component 4 and two sensory descriptors, milky odour and fatty flavour as well as the total $n-6$ polyunsaturated fatty acids in the flesh.

\section{Discussion}

External appearance of gilthead sea bream generally reflected the rearing history of the fish. The description of external appearance has shown that fish from intensive production system can be distinguished from those reared in other systems by an absence of a species-characteristic interorbitary yellow band between the eyes and a darker colour on the dorsal part of the body. These findings are in general accordance with previous results reporting a darker dorsal and head area in intensively farmed gilthead sea bream compared to their wild counterparts (Grigorakis, et al., 2002) or to fish produced in land-based systems (Flos, et al., 2002). The earth ponds traditionally used for semi-intensive, extensive and integrated systems provide natural food to fish (crustaceans and the macroalgae Ulvae have been identified in fish stomach content), that could contribute to maintaining the characteristic golden colour observed in wild fish (Flos, et al., 2002). The yellow-gold line between eyes and the shiny red spot on the gill cover can be an important and easy criterion allowing the consumer to discriminate aquaculture products. These differences of appearance between fish reared under different conditions are further confirmed by flesh colour characteristics evaluated with instrumental measurement or using a trained sensory panel, mainly on cooked product. Fish fillets from integrated system exhibited a darker appearance and more yellowish colour than fish from other production systems that could again be attributed to environmental conditions. The natural productivity of an integrated system enhances access to natural foods and natural pigments that could explain the differences observed on external appearance and flesh colour. Fish from extensive and semi-intensive systems also presented a darker cooked flesh color compared to intensive fish, but in a lesser extend compared to fish from integrated system. As mentioned by Grigorakis (2007) the high lipid content in the flesh could also be a factor which increases the white colour of the cooked flesh in fish from intensive production.

The condition factor and standard length of fish was similar among the various systems contradicting previous results reporting increasing condition index with gilthead sea bream intensification of culture (Flos, et al., 2002). The comparison of distinct rearing systems evidenced significant differences in the whole body composition of sea bream. Fish reared under extensive systems had the lowest whole body lipid deposition and the highest protein content. This was reflected on increased trimming losses for intensive-reared fish compared to the extensive ones, thought no significant differences resulted on the edible part. The flesh protein or lipid composition did not vary significantly among rearing systems, although an increasing lipid flesh content could be observed in fish reared under intensive systems as previously reported by Flos et al. (2002). The fatty acids profile of sea bream flesh tended to differ among rearing systems. Fish from the intensive systems displayed the lowest levels of EPA, DPA and 
DHA, but the highest levels of n- 6 fatty acids. It is common knowledge that fatty acid composition in fish flesh reflects the dietary fatty acid profile. Hence, the high levels in $\mathrm{n}-6$ fatty acids and the large variation in some flesh fatty acids, especially in linoleic acid $(12.3 \pm 7.5)$, in fish reared in intensive systems suggest different degrees of dietary incorporation of plant sources. Over the last decades, fish nutrition research has devoted continued effort in developing sustainable feeds that could provide the adequate levels of long-chain n-3 fatty acids for human nutrition (Bell, et al., 2004; Caballero, et al., 2002; Izquierdo, et al., 2005; Pratoomyot, et al., 2010). Hence, efforts for lipid tailoring of gilthead sea bream quality basically rely on the dietary manipulation of flesh fat deposition and fatty acid profile. In the present study a wide range of variation was observed within fish from the intensive system, suggesting quite distinct incorporation levels of vegetable ingredients (plant protein sources and/or vegetable oil) among fish farms. Despite a general trend of higher level of linoleic acid on samples from intensive system and on the other hand, higher levels of long-chain n-3 fatty acids and higher n-3/n-6 ratios in non-intensively reared fish, probably due to some natural feeding in earth pounds, it is difficult to establish clear quality markers to differentiate gilthead sea bream according to the rearing system. Indeed, regarding fatty acid profile and n-3/n-6 ratio, some of the samples from intensive system did not differ from samples reared in non-intensive conditions. Two out of twenty four samples produce in intensive systems reached a n-3/n-6 ratio of 2 . Therefore, in spite of this ratio being higher in extensive, integrated and semi-intensive systems, indicating a good nutritional quality in those fish, it cannot be an indicator for clearly identifying the kind of rearing system used.

Sensory characteristics of sea bream have been found to differ according to the rearing system. The overall odour intensity of the cooked fillet, as well as some specific descriptors as earthy note, in the case of samples from extensive system, or marine/iodine note in the case of fish from integrated system, have been identified as important criteria contributing to differentiate fish from the different rearing conditions. This earthy characteristic reminds the off flavours problems encountered in continental aquaculture and especially in trout, carp, catfish, salmon or tilapia. In most cases, this was due to the presence of geosmin or 2-methyl iso-borneol produced by cyanobacteria and actinomycetes in certain aquaculture ponds (Tucker, 2000; Vallod, Cravedi, Hillenweck, \& Robin, 2007). In the case of extensive system samples, the natural habitat could also explained that fish took this characteristic while digging the muddy bottom to search food. Regarding the specific marine/iodine odour detected in fish from integrated system it was probably acquired by the ingestion of Ulvae that proliferate in those ponds, as could be confirmed by its presence in sea bream stomach content. Compared to these characteristics, samples from intensive systems presented a more neutral odour and flavour, qualified as fatty and milky, but none of them had an off flavour. The highest level of n- 6 polyunsaturated fatty acids detected in intensive samples could explain the stronger fatty fish odour previously noticed, and partly contribute to the differentiation of those fish from other rearing systems. Finally samples from intensive systems had relatively constant sensory characteristics. The use of sustainable dietary sources, as vegetables oils or plant protein, in intensive systems, as suggested by the flesh fatty acid profile, was not reflected by a great change in sensory characteristics. This result is in agreement with several previous studies on the effect of fish oil and/or fish meal replacement by vegetables sources on fish quality reporting small sensory differences between dietary groups (Fountoulaki, 2009; Grigorakis, 2007). Although the general sensory characteristics were maintained, a variation on fat flavour intensity and perception of a fatty film in mouth could be noticed according to the batch. 
Muscle fibre diameter and white fibres density are important determinant of the textural characteristics of fish flesh (Hurling, Rodell, \& Hunt, 1996; Johnston, Alderson, Sandham, Dingwall, et al., 2000; Periago, et al., 2005). In most markets, consumers show a preference for a firm texture such that fibre density can be regarded as a highly desirable quality attribute. The present results showed a considerable variation in muscle cellularity according to the rearing system. The smaller fibre diameter and higher fibre density observed in fish from intensive and integrated systems are probably the result of a period of intense cell proliferation, as suggested by the higher number of small fibres $(<25 \mu \mathrm{m})$ observed in those fish. Integrated fish were reared under intensive conditions for one year before being transferred to the integrated system for 2 or 6 months, so the muscle histological similarity between intensive and integrated systems confirm the importance of selecting the best production strategy in early developmental stages to improve final flesh quality. In several other fish species, muscle cellularity was shown to vary among fish populations or strains (Johnston, Alderson, Sandham, Mitchell, et al., 2000; Periago, et al., 2005; Valente, et al., 1999) and also have considerable plasticity with respect to abiotic factors, such as diet (Alami-Durante, Médale, Cluzeaud, \& Kaushik, 2010; Bjornevik, Beattie, Hansen, \& Kiessling, 2003; Fauconneau, 1997; Silva, et al., 2009), exercise training (Bjornevik, Karlsen, Johnston, \& Kiessling, 2003; Johnston \& Moon, 1980) and water temperature (Ayala, et al., 2001; Silva, et al., 2007). The recruitment of white fibres is usually associated to fast growth (Johnston, Alderson, Sandham, Mitchell, et al., 2000; Valente, et al., 1999), hence the hyperplastic growth observed in fish from intensive systems could be induced by any of the factors mentioned above, as higher feeding rates in intensive systems, compared to the extensive or semi-intensive ones where feeding rates are usually lower, or by the genetic origin of the fish. In Atlantic salmon, exercise was shown to be a powerful stimulus for muscle hyperthrophy in fish reared in raceways compared to those kept in standard cages (Totland et al. 1987). Similarly, fish from the extensive and semi-intensive systems inhabited large areas, ponds ranging from one to several hectares that could be a powerful stimulus for both red and white muscle fibres' hypertrophy. A positive correlation between fibre density and several textural parameters was reported in different fish species using instrumental methods (Hatae, Yoshimatsu, \& Matsumoto, 1990; Periago, et al., 2005) or a sensory trained panel (Hurling, et al., 1996; Johnston, Alderson, Sandham, Dingwall, et al., 2000). From our overall results, the principal component analysis showed that the strongest correlations between muscle structure and sensory descriptors of texture were obtained for fibrous texture and firmness scores of the cooked fillet. Moreover, flesh firmness showed a significant negative correlation with fibre diameter, but positively correlated with both fibre density and the number of small fibres. Fish from intensive systems had the highest percentage of small fibres and fibre density. Several inter-specific comparisons have already shown significant inverse relationships between average fibre diameter and sensory firmness in cooked fish (Hurling, et al., 1996). The highest scores for texture density and firmness attributed to fish reared in intensive systems were probably due to the mechanical properties of the muscle fibres, as according to Hatae et al (1986) the contribution of connective tissue to the texture is likely to be negligible in cooked fish.

\section{Conclusions}

The present results showed that the yellow-gold line between eyes and the shiny red spot on the gill cover can be an important and easy criterion to discriminate aquaculture products according to the production system. These differences are further confirmed by flesh colour characteristics evaluated with instrumental measurement or using a trained sensory panel. Concerning the nutritional value of the fish, despite a 
general trend of higher level of fat and linoleic acid on samples from intensive systems, and higher n-3 / n-6 ratios in integrated and extensive systems, it is difficult to establish clear quality markers to differentiate gilthead sea bream according to the rearing system. Nevertheless, a fatty and milky odour/flavour could be perceived in samples from intensive system, whereas rearing in earthen pond is more propitious to the development of certain characteristics related to the environment, an earthy note in extensive system, or marine/iodine note in the case of fish from integrated system. Regarding sensory characteristics the highest scores for texture density and firmness in sea bream flesh from intensive system is probably due to smaller white fibres and higher density of fibres in the dorsal muscle of those fish. It can also be concluded that it is possible to modulate the nutritional characteristics of intensively reared fish by transferring them to integrated ponds fertilised with the macroalga Ulva, but not the muscle celullarity. The development of animal welfare friendly products with a low environmental impact, associated with quality assurance schemes, is likely to be increasingly required by the market. Even if larger sampling on non intensive products would be necessary to confirm the observed tendencies, these products can be discriminate from intensive ones by their external appearance and could offer the consumers high levels of long-chain n- 3 fatty acids and good n-3 / n- 6 ratios. On the other hand, non intensive rearing systems in earthen ponds seem more propitious to the development of certain characteristics related to the environment whereas intensive conditions allow more constant sensory characteristics. A clear identification of the product origin and rearing system would allow the consumer to understand that aquaculture can propose different types of products. From the industry perspective the sea bream diversification would allow tailoring fish with distinct attributes or prices, for many segments of the markets, promoting a market-oriented production. 
Table 1. Body traits and proximate whole body composition (\% wet weight) of gilthead sea bream reared under distinct systems in Southern Europe.

\begin{tabular}{|c|c|c|c|c|}
\hline & \multicolumn{4}{|c|}{ Rearing System } \\
\hline & Intensive & $\begin{array}{c}\text { Semi- } \\
\text { Intensive }\end{array}$ & Integrated & Extensive \\
\hline \multicolumn{5}{|l|}{ Body traits } \\
\hline Weight (g) & $\begin{array}{c}396.6 \pm 57.8 \\
a b\end{array}$ & $\begin{array}{c}334.0 \pm 50.9 \\
b\end{array}$ & $\begin{array}{c}464.8 \pm 0.1 \\
a\end{array}$ & $\begin{array}{c}485.1 \pm 4.2 \\
a\end{array}$ \\
\hline Length $(\mathrm{cm})$ & $26.3 \pm 1.3$ & $25.2 \pm 1.5$ & $27.8 \pm 0.1$ & $27.6 \pm 0.2$ \\
\hline Condition factor * & $2.2 \pm 0.2$ & $2.1 \pm 0.1$ & $2.2 \pm 0.1$ & $2.2 \pm 0.1$ \\
\hline \multicolumn{5}{|c|}{ Body fractions (\%) } \\
\hline Viscera & $6.1 \pm 1.1$ & $7.3 \pm 1.0$ & $6.7 \pm 0.6$ & $5.7 \pm 0.5$ \\
\hline Head and bones & $36.9 \pm 2.3$ & $38.8 \pm 2.0$ & $\begin{array}{l}38.6 \pm 0.9 \\
13.1 \pm 0.2\end{array}$ & $38.0 \pm 0.6$ \\
\hline Trimmed fraction & $15.1 \pm 1.7 \mathrm{a}$ & $13.6 \pm 1.1 \mathrm{ab}$ & $a b$ & $12.1 \pm 0.9 b$ \\
\hline Edible part & $42.0 \pm 1.9$ & $40.3 \pm 0.7$ & $41.6 \pm 1.3$ & $44.2 \pm 0.2$ \\
\hline \multicolumn{5}{|c|}{ Whole body composition (\% ww) } \\
\hline Dry matter & $36.8 \pm 2.6$ & $36.9 \pm 2.7$ & $34.1 \pm 5.5$ & $35.2 \pm 2.5$ \\
\hline Ash & $3.5 \pm 0.5$ & $4.1 \pm 0.5$ & $\begin{array}{c}3.5 \pm 0.4 \\
12.4 \pm 4.7\end{array}$ & $4.0 \pm 0.1$ \\
\hline Total lipids & $16.2 \pm 3.1 \mathrm{a}$ & $15.1 \pm 3.0 \mathrm{ab}$ & $\begin{array}{c}a b \\
17.3 \pm 0.2\end{array}$ & $9.4 \pm 2.6 \mathrm{~b}$ \\
\hline Crude protein & $16.6 \pm 0.8 b$ & $17.1 \pm 0.6 \mathrm{ab}$ & $a b$ & $18.6 \pm 0.2 \mathrm{a}$ \\
\hline
\end{tabular}

Values represent mean and standard deviation. In each line, superscript letters indicates significant differences between rearing systems $(p<0.05)$. * Condition factor $=$ Weight/(Length) ${ }^{3} \times 100$. 
Table 2. Protein content (\% wet weight) and total amino acids profile (\% of total amino acids) in raw flesh of sea bream from different rearing systems in Southern Europe.

\begin{tabular}{|c|c|c|c|c|}
\hline & Intensive & Semi-Intensive & Integrated & Extensive \\
\hline Dry Matter (\% ww ) & $29.7(2.5)$ & $29.7(2.0)$ & 26.5 (3.95) & $28.1(1.9)$ \\
\hline Protein (\% ww) & $19.6(1.2)$ & $19.7(0.6)$ & $20.2(0.1)$ & $20.2(0.9)$ \\
\hline $\begin{array}{l}\% \text { of total amino } \\
\text { acids }\end{array}$ & & & & \\
\hline Isoleucine & $7.03 \pm 0.71^{b}$ & $8.30 \pm 0.46^{a}$ & $7.30 \pm 1.17^{\mathrm{ab}}$ & $7.85 \pm 0.01^{a b}$ \\
\hline Leucine & $9.40 \pm 0.64$ & $9.40 \pm 0.58$ & $10.19 \pm 0.88$ & $9.38 \pm 0.16$ \\
\hline Lysine & $5.40 \pm 0.59$ & $5.68 \pm 0.17$ & $5.57 \pm 0.16$ & $4.95 \pm 0.23$ \\
\hline Methionine & $3.56 \pm 0.24$ & $2.86 \pm 0.59^{b}$ & $3.61 \pm 0.47^{a}$ & $3.57 \pm 0.12^{a b}$ \\
\hline Phenylalanine & $4.98 \pm 0.29$ & $5.23 \pm 0.51$ & $5.29 \pm 0.22$ & $5.34 \pm 0.14$ \\
\hline Threonine & $5.84 \pm 0.27$ & $5.86 \pm 0.19$ & $5.70 \pm 0.19$ & $5.65 \pm 0.01$ \\
\hline Valine & $6.39 \pm 0.31$ & $6.02 \pm 0.16$ & $6.21 \pm 0.57$ & $6.29 \pm 0.25$ \\
\hline EAA & $42.61 \pm 1.41$ & $42.35 \pm 1.69$ & $43.88 \pm 1.33$ & $43.04 \pm 0.30$ \\
\hline Alanine & $7.40 \pm 0.46$ & $7.00 \pm 0.20$ & $8.06 \pm 1.30$ & $7.45 \pm 0.08$ \\
\hline Aspartic acid & $12.54 \pm 1.30$ & $13.09 \pm 0.36$ & $12.91 \pm 1.28$ & $12.51 \pm 0.97$ \\
\hline Glutamic acid & $14.94 \pm 1.40$ & $13.85 \pm 1.57$ & $13.06 \pm 0.11$ & $13.17 \pm 0.44$ \\
\hline Glycine & $6.90 \pm 0.54$ & $7.29 \pm 0.28$ & $7.69 \pm 0.21$ & $7.37 \pm 0.002$ \\
\hline Histidine & $2.73 \pm 0.23$ & $2.61 \pm 0.53$ & $2.97 \pm 0.36$ & $3.09 \pm 0.45$ \\
\hline Proline & $4.71 \pm 0.38$ & $5.21 \pm 0.30$ & $5.04 \pm 0.47$ & $4.89 \pm 0.41$ \\
\hline Serine & $4.66 \pm 0.36$ & $4.95 \pm 0.29$ & $4.54 \pm 0.75$ & $4.54 \pm 0.01$ \\
\hline Tyrosine & $2.88 \pm 0.31$ & $2.82 \pm 0.26$ & $2.18 \pm 0.23$ & $3.07 \pm 0.06$ \\
\hline Cystine & $0.59 \pm 0.21$ & $0.83 \pm 0.04$ & $0.66 \pm 0.09$ & $0.85 \pm 0.06$ \\
\hline NEAA & $57.39 \pm 1.41$ & $57.65 \pm 1.69$ & $56.11 \pm 1.33$ & $\mathbf{5 6 . 9 6} \pm 0.30$ \\
\hline EAA / NEAA & $0.74 \pm 0.04$ & $0.74 \pm 0.05$ & $0.78 \pm 0.04$ & $0.75 \pm 0.01$ \\
\hline
\end{tabular}

EAA: Essential Amino Acid NEAA: Non Essential Amino Acid

Tryptophan and Arginine were not analysed by this method. Values represent mean and standard deviation. In each line, superscript letters indicates significant differences between rearing systems $(p<0.05)$ 
Table 3. Total lipid content (\% of wet weight) and fatty acids profile (\% of total fatty acids) in raw flesh of sea bream from different rearing systems in Southern Europe.

\begin{tabular}{|c|c|c|c|c|}
\hline & Intensive & $\begin{array}{c}\text { Semi- } \\
\text { Intensive }\end{array}$ & Integrated & Extensive \\
\hline $\begin{array}{l}\text { Total lipid content } \\
\% \text { wet weight }\end{array}$ & $9.30(2.80)$ & $8.10(2.50)$ & $5.10(3.45)$ & $6.60(1.40)$ \\
\hline $\begin{array}{l}\% \text { of total fatty } \\
\text { acids }\end{array}$ & & & & \\
\hline C14:0 & $7.10 \pm 3.24$ & $4.90 \pm 0.35$ & $5.00 \pm 0.71$ & $2.80 \pm 0.85$ \\
\hline C15:0 & $0.12 \pm 0.22$ & $0.57 \pm 0.05$ & $0.50 \pm 0.00$ & $\underset{\mathrm{a}}{0.85} \pm 0.07$ \\
\hline C16:0 & $27.37 \pm 6.89$ & $22.92 \pm 0.88$ & $22.95 \pm 1.20$ & $27.30 \pm 1.27$ \\
\hline C16:1n-7 & $8.01 \pm 2.38$ & $6.45 \pm 0.24$ & $7.15 \pm 1.06$ & $6.65 \pm 1.06$ \\
\hline C18:0 & $1.25^{\mathrm{b}} 4.82 \quad \pm$ & $0.46^{b^{b}}$ & $5.65 \pm 1.06$ & $\underset{a}{8.60} \pm 0.56$ \\
\hline C18:1n-7 & $4.00 \pm 0.72$ & $4.47 \pm 0.12$ & $4.00 \pm 0.42$ & $3.85 \pm 0.07$ \\
\hline C18:1n-9 & $24.97 \pm 4.82$ & ${ }_{1.31} 25.20 \quad \pm$ & $23.35 \pm 0.64$ & $33.50 \pm 2.97$ \\
\hline C18:2n-6 & $12.25 \pm 7.49$ & $1.011^{10.67 \pm}$ & $7.45 \pm 1.91$ & $1.55 \pm 0.21$ \\
\hline C18:3n-3 & $0.95 \pm 1.33$ & $1.23 \pm 0.12$ & $1.40 \pm 0.00$ & $\mathrm{Nd}$ \\
\hline C20: 0 & $0.30^{0.13 \pm}$ & $0.75 \pm 0.17$ & $0.70 \pm 0.42^{\mathrm{a}}$ & $\underset{\mathrm{ab}}{0.50 \pm 0.70}$ \\
\hline C20:1n-9 & $2.54 \pm 1.48$ & $3.15 \pm 0.19$ & $1.40 \pm 0.28$ & $1.00 \pm 0.28$ \\
\hline$C 20: 4 n-6$ & $0.21^{d}{ }^{d}=8 \pm$ & $\begin{array}{l}0.47 \pm \\
0.05^{\mathrm{c}}\end{array}$ & $1.05 \pm 0.64^{b}$ & $2.45 \pm 0.49^{a}$ \\
\hline$C 20: 5 n-3$ & $2.80 \pm 2.23$ & $3.62 \pm 0.71$ & $6.75 \pm 0.78$ & $3.20 \pm 0.28$ \\
\hline C22:1n-9 & $0.66 \pm 0.38$ & $2.40 \pm 0.42$ & $0.40 \pm 0.56$ & $\mathrm{Nd}$ \\
\hline$C 22: 2 n-6$ & $\mathrm{Nd}$ & $\mathrm{Nd}$ & $\mathrm{Nd}$ & $1.70 \pm 2.40$ \\
\hline $\mathrm{C} 24: 0$ & $0.22^{0.08 \pm}$ & $\underset{\mathrm{a}}{0.77} \pm 0.09$ & $0.30 \pm 0.42$ & $0.50 \pm 0.71^{a}$ \\
\hline$C 22: 5 n-3$ & $1.06 \pm 1.40$ & $\underset{\mathrm{ab}}{2.00} \pm 0.18$ & $4.15 \pm 0.92^{a}$ & $2.20 \pm 0.71$ \\
\hline$C 22: 6 n-3$ & $\underset{b}{2.85} \pm 2.79$ & $\begin{aligned} & 6.45 \\
& 0.60^{\mathrm{a}} \pm \\
&\end{aligned}$ & $7.75 \pm 0.92^{a}$ & $\underset{\mathrm{ab}}{2.90} \pm 1.13$ \\
\hline$\sum$ saturated & $39.62 \pm$ & $34.90 \pm 1.43$ & $35.10 \pm 0.71$ & $40.55 \pm 1.63$ \\
\hline$\sum$ & 10.81 & $40.67 \pm 0.69$ & $36.30 \pm 2.12$ & $45.00 \pm 2.12$ \\
\hline monounsaturated & $40.20 \pm 4.67$ & $24.45 \pm 1.38$ & $28.55 \pm 1.34$ & $14.00 \pm 0.00$ \\
\hline$\sum$ polyunsaturated & $20.00 \pm 9.71$ & & & \\
\hline$\sum n-3$ & $7.67 \pm 7.09$ & $13.30 \pm 1.46$ & $20.05 \pm 2.62$ & $8.30 \pm 2.12$ \\
\hline$\sum n-6$ & $12.33 \pm 7.45$ & $11.15 \pm 1.05$ & $8.50 \pm 1.27$ & $5.70 \pm 2.12$ \\
\hline Ratio $\sum n-3 / \sum n-6$ & $0.79 \pm 0.95$ & $1.20 \pm 0.19$ & $2.41 \pm 0.67$ & $1.64 \pm 0.98$ \\
\hline
\end{tabular}

Values represent mean and standard deviation. Nd : under the detection level.

In each line, different superscript letters indicate significant differences between rearing system $(p<0.05)$. 
Table 4. Analysis of colour parameters $\left(L^{*}, a^{*} b^{*}\right)$ on raw and cooked flesh and muscle cellularity of sea bream from different rearing system in Southern Europe.

\begin{tabular}{|c|c|c|c|c|}
\hline & \multicolumn{4}{|c|}{ Rearing System } \\
\hline & Intensive & Semi-Intensive & Integrated & Extensive \\
\hline \multicolumn{5}{|l|}{ Colour parameters } \\
\hline \multicolumn{5}{|l|}{ Raw fillets } \\
\hline$L^{*}$ & $43.51 \pm 3.73 \mathrm{a}$ & $42.78 \pm 4.2 \mathrm{a}$ & $37.65 \pm 3.21 b$ & $43.89 \pm 3.04 \mathrm{a}$ \\
\hline$a^{*}$ & $-2.21 \pm 1.05 a$ & $-3.29 \pm 0.99 a b$ & $-3.05 \pm 0.98 b$ & $-1.92 \pm 0.95 a$ \\
\hline$b^{*}$ & $1.82 \pm 2.95 \mathrm{C}$ & $6.58 \pm 3.93 \mathrm{~b}$ & $9.69 \pm 2.49 \mathrm{a}$ & $1.94 \pm 1.6 \mathrm{c}$ \\
\hline \multicolumn{5}{|l|}{ Cooked fillets } \\
\hline$L^{*}$ & $79.77 \pm 3.97 \mathrm{a}$ & $79.99 \pm 2.63 \mathrm{a}$ & $74.69 \pm 4.21 \mathrm{c}$ & $78.13 \pm 4.28 b$ \\
\hline$a^{*}$ & $-2.9 \pm 0.90 b$ & $-2.31 \pm 1.1 \mathrm{a}$ & $-2.25 \pm 1.31 \mathrm{a}$ & $-2.36 \pm 1.04 \mathrm{a}$ \\
\hline$b^{\star}$ & $12.25 \pm 2.52 \mathrm{c}$ & $14.54 \pm 1.89 \mathrm{~b}$ & $19.18 \pm 2.99 \mathrm{a}$ & $12.54 \pm 1.56 \mathrm{c}$ \\
\hline $\begin{array}{l}\text { Dorsal total section area }(\mathrm{mm} 2) \\
\text { Subcutaneous adipose tissue } \\
\text { area }(\mathrm{mm} 2)\end{array}$ & $\begin{array}{c}510.86 \pm 111.12 \mathrm{c} \\
38.99 \pm 15.71\end{array}$ & $\begin{array}{c}585.97 \pm 120.58 \mathrm{~b} \\
36.75 \pm 21.45\end{array}$ & $\begin{array}{c}512.87 \pm 26.37 \mathrm{bc} \\
17.85 \pm 6.71\end{array}$ & $\begin{array}{c}863.36 \pm 194.14 \mathrm{a} \\
44.15 \pm 15.19\end{array}$ \\
\hline \multicolumn{5}{|l|}{ White Muscle } \\
\hline $\begin{array}{l}\text { Dorsal area }(\mathrm{mm} 2) \\
\text { Total dorsal fibres number } \mathrm{x} \\
1000\end{array}$ & $\begin{array}{l}385.09 \pm 75.65 \mathrm{c} \\
146.08+29.67 \mathrm{a}\end{array}$ & $\begin{array}{l}467.21 \pm 83.26 \mathrm{~b} \\
114.84+26.98 b\end{array}$ & $\begin{array}{l}410.77 \pm 7.46 \mathrm{bc} \\
146.78+10.03 \mathrm{ab}\end{array}$ & $\begin{array}{l}681.94 \pm 159.53 \mathrm{a} \\
135.63+31.16 \mathrm{ab}\end{array}$ \\
\hline Diameter of fibres $(\mu \mathrm{m})$ & $\begin{array}{l}59.12 \pm 5.4 \mathrm{a} \\
\end{array}$ & $\begin{array}{l}114.84 \pm \angle 0.98 \mathrm{D} \\
70.59 \pm 9.12 \mathrm{~b}\end{array}$ & $57.49 \pm 4.85 \mathrm{a}$ & $\begin{array}{l}135.03 \pm 31.10 \mathrm{do} \\
79.28 \pm 10.95 \mathrm{c}\end{array}$ \\
\hline No fibres/ mm2 & $384.21 \pm 74.81 \mathrm{a}$ & $263.37 \pm 70.49 \mathrm{~b}$ & $395.90 \pm 69.82 \mathrm{a}$ & $206.27 \pm 54.54 b$ \\
\hline$\%$ fibres $<25 \mu \mathrm{m}$ & $8.38 \pm 5.2 \mathrm{a}$ & $1.89 \pm 2.86 \mathrm{~b}$ & $6.22 \pm 1.84 \mathrm{ab}$ & $0.35 \pm 0.71 \mathrm{~b}$ \\
\hline \multicolumn{5}{|l|}{ Red Muscle } \\
\hline $\begin{array}{l}\text { Dorsal area }(\mathrm{mm} 2) \\
\text { Total dorsal fibres number } x \\
1000\end{array}$ & $\begin{array}{l}13.76 \pm 5.46 \mathrm{a} \\
18.70 \pm 7.16 \mathrm{a}\end{array}$ & $\begin{array}{l}10.38 \pm 4.68 b \\
13.31 \pm 6.12 b\end{array}$ & $\begin{array}{l}7.67 \pm 1.91 \mathrm{ab} \\
9.03 \pm 1.80 \mathrm{ab}\end{array}$ & $\begin{array}{l}13.56 \pm 6.54 \mathrm{ab} \\
11.15 \pm 3.30 \mathrm{~b}\end{array}$ \\
\hline Diameter of fibres $(\mu \mathrm{m})$ & $30.72 \pm 3.54 b$ & $32.54 \pm 3.04 b$ & $33.20 \pm 0.59 b$ & $40.19 \pm 5.01 \mathrm{a}$ \\
\hline No fibres/ mm2 & $.429 .15 \pm 390.18 a$ & $.293 .44 \pm 270.43 \mathrm{a}$ & $1211.33 \pm 62.54 \mathrm{a}$ & $920.38 \pm 259.79 b$ \\
\hline$\%$ fibres $<25 \mu \mathrm{m}$ & $33.94 \pm 12.77 \mathrm{a}$ & $28.61 \pm 9.55 \mathrm{a}$ & $27.50 \pm 1.27 \mathrm{ab}$ & $10.40 \pm 9.48 b$ \\
\hline
\end{tabular}

Values represent mean and standard deviation of individual fish. In each line, superscript letters indicate significant differences between rearing system $(p<0.05)$. 


\section{Figures}

Figure 1a

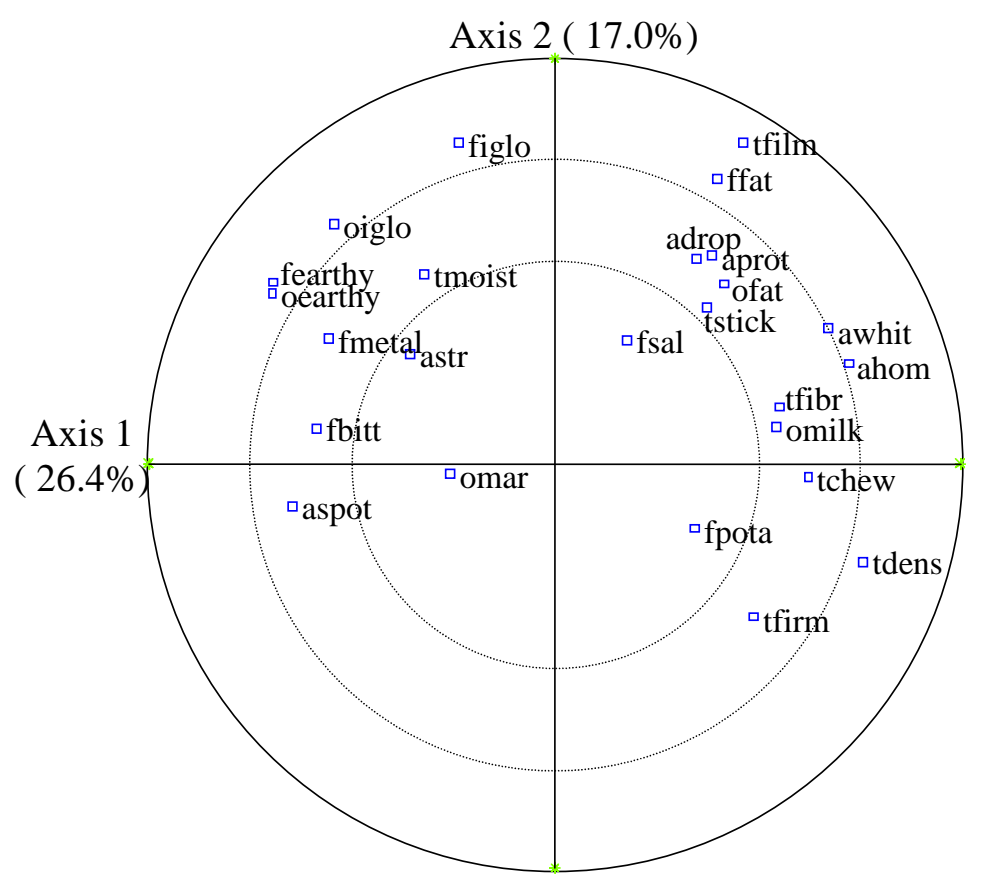

Figure 1 a) Variables correlation on the first plane of the standardized principal component analysis. Sensory descriptors: odour, global intensity (oiglo), fat fish (ofat), marine-iodin like (omar), milky (omilk) earthy (oearthy); appearance, colour homogeneity (ahom), white colour (awhit), coagulated proteins (aprot), brown spots (aspot), black stria (astr), fat droplets in gravy (adrop); texture, firmness (tfirm), density of the flesh (tdens), moisture (tmoist), fibrous (tfibr), sticky (tstick), chewiness (tchew), fat film (tfilm); flavour. global intensity (figlo), fat fish (ffat), potatoe (fpota), earthy (fearthy), salty taste (fsal), bitter taste (tbitt), metallic taste (tmetal).

Figure 1b

Figure $1 \mathrm{~b}$ ) Projection of samples in the plane 1-2 of the principal component analysis on sensory descriptors. I, intensive system samples (I1 samples evaluated in first sessions and 12 samples included and evaluated in a session with other rearing system samples); Integrated_2m and Integrated_6m, samples stayed 2 or 6 months in integrated system; Ext1, extensive system samples from Esteros in Spain and Valliculture in Italy; Semi Int, semi intensive system samples from Portugal. 
Axis 2 (17.0\%)

\begin{tabular}{|l|l|l|l|l|}
\hline Axis 1 \\
$(26.4 \%)$
\end{tabular}

Figure 2

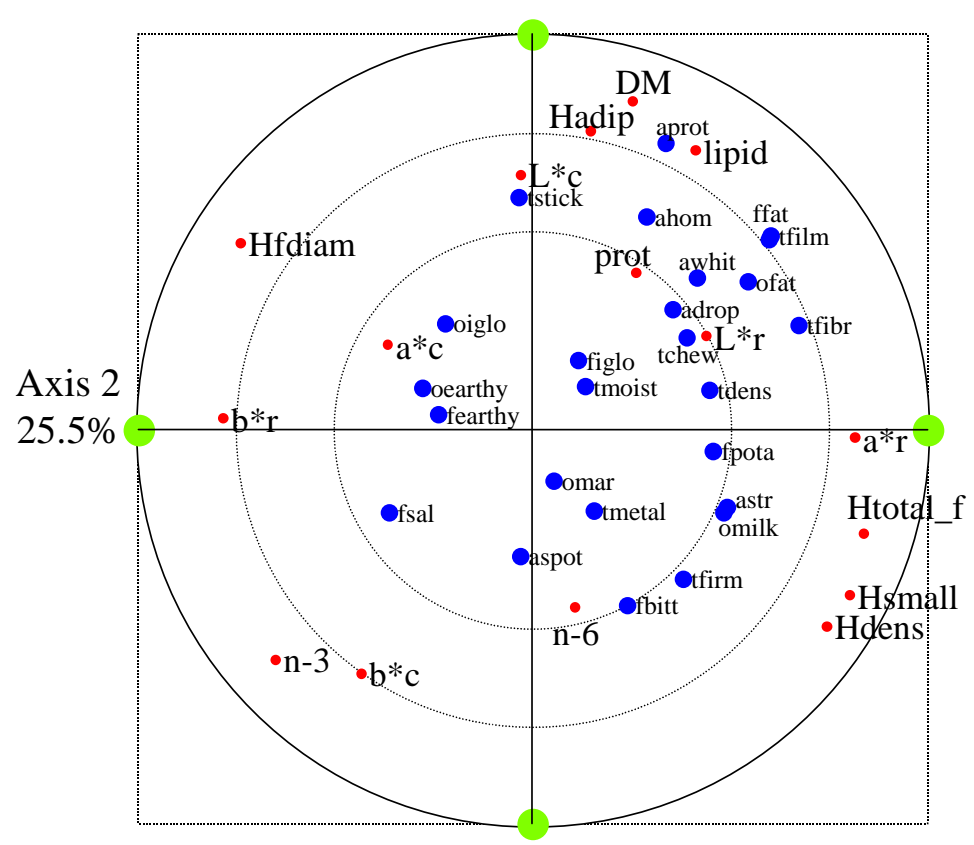

Axis 1 ( 31.3\%) 
Correlation between sensory descriptors and component 1 and 2 of the principal component analysis from chemical, physical and histological parameters

Chemical parameters: Dry matter (DM), protein content (prot), flesh lipid content (lip), $n-3$ polyunsaturated fatty acids ( $n-3), n-6$ polyunsaturated fatty acids $(n-6)$. Colour parameters : $L^{*}$, $a^{*}$ and $b^{*}$ on raw $(r)$ and cooked (c)samples. Histological parameters: Total fibres number (Htotal ff), subcutaneous adipose tissue (Hadip), percentage of small fibres (Hsmall), density of fibres (Hdens), fibres diameter (Hfdiam)

Sensory descriptors: odour, global intensity (oiglo), fat fish (ofat), marine-iodin like (omar), milky (omilk) earthy (oearthy); appearance, colour homogeneity (ahom), white colour (awhit), coagulated proteins (aprot), brown spots (aspot), black stria(astr), fat droplets in gravy (adrop); texture, firmness (tfirm), density of the flesh (tdens), moisture (tmoist), fibrous (tfibr), sticky (tstck), chewiness (tchew), fat film (tfilm); flavour. global intensity (figlo), fat fish (ffat), potatoe (fpota), earthy (fearthy), salty taste (fsal), bitter taste (tbitt), metallic taste (tmetal)

\section{Aknowledgements}

This research has been carried out with the financial support from the Commission of the European Communities, specific RTD programme "Specific Support to Policies", SSP-2005-44483 "SEACASE - Sustainable extensive and semi-intensive coastal aquaculture in Southern Europe, and does not necessarily reflect the European Commission views and in no way anticipates the Commission's future policy in this area. Authors want to deeply thank Jérôme Hussenot (Ifremer), Sophie Cariou (Ferme du Douhet, France), Giovanna Marino (ICRAM), Tommaso Petochi (ICRAM), Manuel Yufera (CSIC), and Ana Ramalho (CCMAR) for sampling and processing fish for quality determination.

\section{References}

Alami-Durante, H., Médale, F., Cluzeaud, M., \& Kaushik, S. J. (2010). Skeletal muscle growth dynamics and expression of related genes in white and red muscles of rainbow trout fed diets with graded levels of a mixture of plant protein sources as substitutes for fishmeal. Aquaculture, 303(1-4), 50-58.

AOAC. (2006). Official methods of analysis of AOAC International (18 ed.). Maryland, USA: AOAC International.

Ayala, M. D., Lopez-Albors, O., Gil, F., Garcia-Alcazar, A., Abellan, E., Alarcon, J. A., Alvarez, M. C., Ramirez-Zarzosa, G., \& Moreno, F. (2001). Temperature effects on muscle growth in two populations (Atlantic and Mediterranean) of sea bass, Dicentrarchus labrax L. Aquaculture, 202(3-4), 359-370.

Bagni, M., Civitareale, C., Priori, A., Ballerini, A., Finoia, M., Brambilla, G., \& Marino, G. (2007). Pre-slaughter crowding stress and killing procedures affecting quality and welfare in sea bass (Dicentrarchus labrax) and sea bream (Sparus aurata). Aquaculture Engeneering, 263, 52-60.

Bell, J., Henderson, R., Tocher, D., \& Sargent, J. (2004). Replacement of dietary fish oil with increasing levels of linseed oil: Modification of flesh fatty acid compositions in Atlantic salmon (Salmo salar) using a fish oil finishing diet. Lipids, 39(3), 223-232.

Bermejo, N. (2000). Implementation of a sign of superior quality for aquaculture products: The experience of Label rouge sea bass in France. In Cahiers Options Méditerranéennes, Global quality assessment in Mediterranean aquaculture (Vol. 51, pp. 103-109). Zaragoza: CIHEAM. 
Bjornevik, M., Beattie, C., Hansen, T., \& Kiessling, A. (2003). Muscle growth in juvenile Atlantic salmon as influenced by temperature in the egg and yolk sac stages and diet protein level. Journal of Fish Biology, 62(5), 1159-1175.

Bjornevik, M., Karlsen, O., Johnston, I. A., \& Kiessling, A. (2003). Effect of sustained exercise on white muscle structure and flesh quality in farmed cod (Gadus morhua L.). Aquaculture Research, 34(1), 55-64.

Caballero, M. J., Obach, A., Rosenlund, G., Montero, D., Gisvold, M., \& Izquierdo, M. S. (2002). Impact of different dietary lipid sources on growth, lipid digestibility, tissue fatty acid composition and histology of rainbow trout, Oncorhynchus mykiss. Aquaculture, 214(1-4), 253.

Calabretti, A., Cateni, F., Procida, G., \& Favretto, L. G. (2003). Influence of environmental temperature on composition of lipids in edible flesh of rainbow trout (Oncorhynchus mykiss). Journal of the Science of Food and Agriculture, 83, 14931498.

Cardinal, M., Cornet, J. Donnay-Moreno, C., Gouygou, J. P., Bergé, J.P., Rocha, E., Soares, S., Escórcio, C., Borges, P. \& Valente, L.M.P. (2010). Seasonal variation of physical, chemical and sensory characteristics of sea bream (Sparus aurata) reared under intensive conditions in Southern Europe. Food Control. In Press.

Cowey, C. B. (1993). Some effects of nutrition on flesh quality of cultured fish. In S. J. Kaushik \& P. Luquet (Eds.), Fish Nutrition in Practice (pp. 227-236). Paris: INRA.

Crooke, W. M., \& Simpson, W. E. (1971). Determination of ammonium in Kjeldhal digestes of crops by an automated procedure. Journal of the Science of Food and Agriculture, 22(1), 9-\&.

Dendrinos, P., \& Thorpe, J. P. (1985). Effects of reduced salinity on growth and body composition in the european bass (Dicentrarchus labrax). Aquaculture Engeneering, 49, 333-358.

Dias, J., Conceição, L. E. C., Ribeiro, A. R., Borges, P., Valente, L. M. P., \& Dinis, M. T. (2009). Practical diet with low fish-derived protein is able to sustain growth performance in gilthead seabream (Sparus aurata) during the grow-out phase. Aquaculture, 293(3-4), 255-262.

Eroldogan, O. T., Kumlu, M., \& Aktas, M. (2004). Optimum feeding rates for European sea bass Dicentrarchus labrax L. reared in seawater and freshwater. Aquaculture Engeneering, 231, 501-515.

FAO. (2009). The state of the world fisheries and aquaculture. Rome, Italy: FAO, Fisheries and Aquaculture Department.

Fauconneau, B., Andre S., Chmaitilly J., Bail P. Y., Krieg F., Kaushik S. J. (1997). Control of skeletal muscle fibres and adipose cells size in the flesh of rainbow trout. Journal of Fish Biology, 50(2), 296-314.

FEAP. (2008). Production and price reports of member associations of the FEAP. In $P$ (2001-2008): Federation of European Aquaculture Producers (http://www.feap.info/production/euproduction/productionreport_en.asp).

Ferreira Pinto, J., Nunes, M. L., \& Cardoso, C. (2007). Feeding interruption and quality of cultured gilthead sea bream. Food Chemistry, 100(4), 1504-1510.

Flos, R., Reig, L., Oca, J., \& Ginovart, M. (2002). Influence of marketing and different land-based systems on gilthead sea bream (Sparus aurata) quality. Aquaculture International, 10(3), 189-206.

Folch, J., Lees, M., \& Stanley, G. H. S. (1957). A simple method for the isolation and purification of total lipids from animal tissues. Journal of Biological Chemistry, 226(1), 497-509.

Frewer, L. J., Kole, A., Kroon, S. M. A. V. d., \& Lauwere, C. d. (2005). Consumer Attitudes Towards the Development of Animal-Friendly Husbandry Systems. Journal of Agricultural and Environmental Ethics, 18(4), 345-367.

Grigorakis, K. (2007). Compositional and organoleptic quality of farmed and wild gilthead sea bream (Sparus aurata) and sea bass (Dicentrarchus labrax) and factors affecting it: A review. Aquaculture, 272(1-4), 55-75. 
Grigorakis, K., Alexis, M. N., Taylor, K. D. A., \& Hole, M. (2002). Comparison of wild and cultured gilthead sea bream (Sparus aurata); composition, appearance and seasonal variations. International Journal of Food Science and Technology, 37(5), 477484.

Hatae, K., Tobimatsu, A., Takeyama, m., \& Matsumoto, J. J. (1986). Contribution of connective tissues on the texture difference of various fish species. Bulletin of the Japonese Society of Scientific Fisheries, 52, 2001-2007.

Hatae, K., Yoshimatsu, F., \& Matsumoto, J. J. (1990). Role of Muscle Fibers in Contributing Firmness of Cooked Fish. Journal of Food Science, 55(3), 693-696.

Hillestad, M., \& Johnsen, F. (1994). High-energy/low-protein diets for Atlantic salmon: effects on growth, nutrient retention and slaughter quality. Aquaculture, 124(1-4), 109.

Hurling, R., Rodell, J. B., \& Hunt, H. D. (1996). Fiber diameter and fish texture. Journal of Texture Studies, 27(6), 679-685.

Hussenot, J. M. E. (2003). Emerging effluent management strategies in marine fishculture farms located in European coastal wetlands. Aquaculture, 226(1-4), 113-128.

Izquierdo, M. S., Montero, D., Robaina, L., Caballero, M. J., Rosenlund, G., \& Gines, R. (2005). Alterations in fillet fatty acid profile and flesh quality in gilthead seabream (Sparus aurata) fed vegetable oils for a long term period. Recovery of fatty acid profiles by fish oil feeding. Aquaculture, 250(1-2), 431.

Johnston, I. A., Alderson, R., Sandham, C., Dingwall, A., Mitchell, D., Selkirk, C., Nickell, D., Baker, R., Robertson, B., Whyte, D., \& Springate, J. (2000). Muscle fibre density in relation to the colour and texture of smoked Atlantic salmon (Salmo salar L.). Aquaculture, 189(3-4), 335-349.

Johnston, I. A., Alderson, R., Sandham, C., Mitchell, D., Selkirk, C., Dingwall, A., Nickell, D., Baker, R., Robertson, B., Whyte, D., \& Springate, J. (2000). Patterns of muscle growth in early and late maturing populations of Atlantic salmon (Salmo salar L.). Aquaculture, 189(3-4), 307-333.

Johnston, I. A., \& Moon, T. W. (1980). Exercise training in skeletal muscle of brook trout (Salvelinus fontinalis). Journal of Experimental Biology, 87(1), 177-194.

Ky, C.L. (2007). Caractérisation des hybrides interspécifiques de bars en élevage Rapport final Convention OFIMER $n^{\circ}$ 040/05/C.

Periago, M. J., Ayala, M. D., Lopez-Albors, O., Abdel, I., Martinez, C., Garcia-Alcazar, A., Ros, G., \& Gil, F. (2005). Muscle cellularity and flesh quality of wild and farmed sea bass, Dicentrarchus labrax L. Aquaculture, 249(1-4), 175-188.

Pratoomyot, J., Bendiksen, E. A.., Bell, J. G., \& Tocher, D. R. (2010). Effects of increasing replacement of dietary fishmeal with plant protein sources on growth performance and body lipid composition of Atlantic salmon (Salmo salar L.). Aquaculture, 305(1-4), 124-132.

Shearer, K. D. (1994). Factors affecting the proximate composition of cultured fishes with emphasis on salmonids. Aquaculture, 119(1), 63-88.

Silva, P., Rocha, E., Olmedo, M., Alvarez-Blàzquez, B., Galante, M. H., \& Valente, L. M. P. (2007). Temperature effects on muscle fibres number at hatch and first feeding in blackspot seabream (Pagellus bogaraveo). Archiv fur Tierzucht, 50(SPEC. ISS.), 0607.

Silva, P., Valente, L. M. P., Galante, M. H., Andrade, C. A. P., Monteiro, R. A. F., \& Rocha, E. (2009). Dietary protein content influences both growth and size distribution of anterior and posterior muscle fibres in juveniles of Pagellus bogaraveo (Brunnich). Journal of Muscle Research and Cell Motililty, In Press.

Tejada, M., Huidobro, A., \& Mohamed, G. F. (2006). Evaluation of Two Quality Indices Related to Ice Storage and Sensory Analysis in Farmed Gilthead Seabream and Seabass. Food Science and Technology International, 12(3), 261-268.

Tucker, C. S. (2000). Off-Flavor Problems in Aquaculture. Reviews in Fisheries Science, 8(1), 45 - 88. 
Valente, L. M. P., Rocha, E., Gomes, E. F. S., Silva, M. W., Oliveira, M. H., Monteiro, R. A. F., \& Fauconneau, B. (1999). Growth dynamics of white and red muscle fibres in fast- and slow-growing strains of rainbow trout. Journal of Fish Biology, 55(4), 675-691. Vallod, D., Cravedi, J., Hillenweck, A., \& Robin, J. (2007). Analysis of the off-flavor risk in carp production in ponds in Dombes and Forez (France). Aquaculture International, 15(3), 287-298.

Verbeke, W., Sioen, I., Brunsø, K., De Henauw, S., \& Van Camp, J. (2007). Consumer perception versus scientific evidence of farmed and wild fish: exploratory insights from Belgium. Aquaculture International, 15(2), 121-136.

Vergara, J. M., Lopez-Calero, G., Robaina, L., Caballero, M. J., Montero, D., Izquierdo, M. S., \& Aksnes, A. (1999). Growth, feed utilization and body lipid content of gilthead seabream (Sparus aurata) fed increasing lipid levels and fish meals of different quality. Aquaculture, 179(1-4), 35.

Zar, J. H. (1999). Biostatistical Analysis (Fourth ed.). London: Prentice Hall. 